\title{
Addressing the challenges of practicing breast cytology in a tertiary teaching hospital in Kenya
}

\author{
Authors: Kumar $\mathbf{N}^{\mathbf{1}}$ MD, Sayed S ${ }^{1}$ M.Med (Pathol), Moloo Z ${ }^{1}$ MD, Chauhan $\mathbf{R}^{2}$ MS, and Wasike $\mathbf{R}^{2}$ MMed (Surgery) \\ Affiliations: 1. Department of Pathology, Aga Khan University Hospital, Nairobi. 2. Department of Surgery, Aga Khan University \\ Hospital, Nairobi, Kenya Correspondence: Neeta Kumar, MD, Department of Pathology, Aga Khan University Hospital, Third \\ Parklands P.0. Box 30270-00100 Nairobi, Kenya Fax 3749196 E mail kumar_neeta@hotmail.com, neeta.kumar@aku.edu
}

\section{Abstract}

\section{Objectives}

To assess diagnostic accuracy of breast cytology through histological correlation and identify reasons for diagnostic pitfalls.

\section{Methods}

A total of 2700 cases were reported in cytology during the study period of 14 months, of which 1100 (40\%) were from breast lesions. Only 96 (9\%) cases had histological follow up in the form of core biopsy, lumpectomy and/or mastectomy. The cases in which cytology diagnosis did not match with histology diagnosis were reviewed by two pathologists and reasons for the diagnostic pitfalls in cytology were recorded. Sensitivity, specificity, positive predictive value (PPV) and negative predictive value (NPV) of cytology were calculated.

\section{Results}

Seventy cases (73\%) had no cytohistologic discrepancy, three cases were reported as unsatisfactory while $23(24 \%)$ showed discrepancy with his- tology. Interpretation errors occurred in 16 cases in 3 categories (benign C2, atypical $C 3$ and suspicious (4). There were 2 false negatives (C2) and 14 false positives (C3 and C4). Majority (58\%, 8 out of 14) of the errors in the false positive groups were due to the poor quality of smears received from our satellite centres.

Misclassification of subtypes within benign and malignant categories occurred in 2 cases each due to overlapping features. Sampling errors occurred in three cases due to inherent nature of the lesion. Sensitivity of our FNA was $91 \%$, Specificity was $79 \%$, Positive predictive value (PPV) $59 \%$ and negative predictive value (NPV) was $96 \%$.

\section{Conclusions}

There was no major discrepancy to influence the management or prognosis significantly. Minor discrepancies resulted due to sampling and interpretation errors. Poor quality smear emerged as a major cause of interpretation errors. This calls for corrective measures to be applied for both sample providers and pathologists.

\section{Introduction}

Breast cancer accounted for $23.3 \%$ of all cancers in women in Kenya during the year 2000-2002 (1). Almost two thirds of these patients presented at advanced stages. Fine needle aspiration (FNA) can be a cost effective tool for an early and rapid diagnosis (2). Facilities for doing FNA are not available to a large population of patients due to shortage of skilled operators and cytopathologists. The limited numbers of existing pathologists try to cope with the burden of performing FNA procedures and interpretation in addition to their heavy histopathology workload.

The Pathology Department at our University Hospital has been running an FNA clinic since 2005. A "One Stop Breast Clinic" at our hospital provides the triple test approach and FNA is often the first modality used in palpable lumps as part of an immediate assessment, so that patients could go home the same day with a diag- nosis. The cytopathologist (NK) and residents perform FNA of all palpable breast masses referred from breast clinic and other hospitals (3). In addition nipple discharge cytology is often requested in suspicious cases. Our laboratory also receives FNA and nipple discharge smears from outreach centres, private hospitals, clinics and laboratories in and around Nairobi where FNA is performed by surgeons, clinicians, radiologists, clinical officers and general practitioners not formally trained or skilled in FNA technique.

Variable levels of operator and interpreter skills are major challenges in cytology. As histology is considered the gold standard for tissue diagnosis, cytohisto correlation is the main quality assurance measure in cytology service. The objectives of this study were to assess diagnostic accuracy and identify reasons for diagnostic pitfalls of breast cytology in a setting with high incidence of breast cancer and where FNA procedure is often performed by non pathologists and clinical data is sketchy. 


\begin{tabular}{|c|c|c|c|c|}
\hline $\begin{array}{l}\text { Case } \\
\text { no }\end{array}$ & $\begin{array}{l}\text { Cyto diagnosis } \\
\text { Initial }\end{array}$ & $\begin{array}{l}\text { Cyto diagnosis } \\
\text { Review by cytopathologist }\end{array}$ & Histo diagnosis & Reason for diagnostic pitfall in cytology \\
\hline 1. & Duct ectasia & Duct ectasia & Ductal carcinoma in situ & $\begin{array}{l}\text { Sampling error as malignant cells not seen in cytology } \\
\text { smears. (False negative cytology) }\end{array}$ \\
\hline 2. & Duct ectasia & $\begin{array}{l}\text { Papillary lesion. } \\
\text { Category upgraded to atypical (C3) }\end{array}$ & Papillomatosis & $\begin{array}{l}\text { Interpretation error due to lack of experience in diagnosis } \\
\text { of papillary lesions on nipple discharge. }\end{array}$ \\
\hline 3. & Fibrocystic disease & $\begin{array}{l}\text { Benign proliferative lesion but rule out } \\
\text { malignancy considering age } 76 y r s\end{array}$ & $\begin{array}{l}\text { Papillary carcinoma with prominent } \\
\text { intraductal component }\end{array}$ & $\begin{array}{l}\text { Interpretation error due to lack of experience in diagnosis } \\
\text { and overlapping features of papillary lesions with fibrocys- } \\
\text { tic disease. (False negative cytology) }\end{array}$ \\
\hline 4. & Fibrocystic disease & Benign proliferative lesion & Papillomatosis & Sampling error due to inherent nature of the lesion \\
\hline 5. & Fibrocystic disease & Benign proliferative lesion & $\begin{array}{l}\text { Radial scar with aypical ductal hyper- } \\
\text { plasia }\end{array}$ & $\begin{array}{l}\text { Sampling error due to inherent nature of the lesion. (False } \\
\text { negative cytology) }\end{array}$ \\
\hline 6. & Fibroadenoma & Fibroadenoma & Hamartoma & $\begin{array}{l}\text { Misclassification of both benign lesions due to overlapping } \\
\text { features }\end{array}$ \\
\hline 7. & Fibroadenoma & Fibroadenoma & Tubular adenoma & $\begin{array}{l}\text { Misclassification of both benign lesions due to overlapping } \\
\text { features }\end{array}$ \\
\hline
\end{tabular}

Table 1: Cytohisto correlation and reasons of diagnostic pitfall in cytology (Category benign C2, No.of cases $=7$ )

\section{Methods}

A total of 2700 cases were reported in cytology during the study period of 14 months (January 2009 to February 2010), of which 1100 (40\%) were from breast (including FNAs and 60 nipple discharges). Only 96 (9\%) cases had histological follow up in the form of core biopsy, lumpectomy and/or mastectomy and formed the material of this study.

We use the C1-C5 reporting system (NCI 1996): C1 inadequate; $\mathrm{C} 2$ benign; $\mathrm{C} 3$ atypical, probably benign; C4 suspicious; and C5 malignant (4). Biopsy is recommended for the C3 and C4 categories. Clinically or radiologically suspicious or malignant cases with negative or unsatisfactory cytology have a core biopsy. When triple assessment is concordant, final treatment may be ensued without open biopsy.

The cytology cases in which cytology diagnosis did not match with histology diagnosis (discrepant cases) were reviewed by two pathologists (NK, SS) independently and then together on a multiheader microscope to analyse the cause/s which could have led to diagnostic error (pitfall) in cytology with histology as the gold standard. The cytopathologist's expertise and literature review were used to analyse the causes of diagnostic pitfalls.

The discrepancy was rated as "minor discrepancy" when there was no impact of cytological diagnosis on clinical management (e.g. cytology report of fibrocystic disease found to be fibroadenoma or tubular adenoma on histology or vice versa). It was considered a "major discrepancy" when a cytological diagnosis was likely to influence the management and prognosis significantly such as cytology report of benign ( C2) found malignant on histology or cytology report of atypical (C3) suspicious (C4) or malignant (C5) found benign on histology.

Sensitivity, specificity, positive predictive value (PPV) and negative predictive value (NPV) were calculated using the standard statistical methods from SPSS software.

\section{Results}

Seventy out of 96 (73\%) cases had no cytohistologic discrepancy. There were 52 cases of benign cytology (C2 category) confirmed as benign lesions on histology and included fibroadenoma (33 cases), tubular adenoma ( 2 cases), fibrocystic disease ( 6 cases), mastitis ( 5 cases), fat necrosis ( 1 case), gynecomastia ( 1 case), breast abscess ( 1 case), lactating adenoma ( 1 case), and intraductal papillomatosis (2 cases). Eighteen cases of malignant (C5) and suspicious (C4) cytology were confirmed to be malignant tumours on histology. Cytology smears in 12 ( 8 benign and 4 malignant) of these 70 cases (16.8\%) were received from satellite centres.

Three cases (2\%) with unsatisfactory (C1) cytology report due to fibroadipose tissue showed infiltrating lobular carcinoma (ILC) and lipoma (2 cases) on histology. Twenty three $(24 \%)$ cases (FNA in 21 cases and nipple 


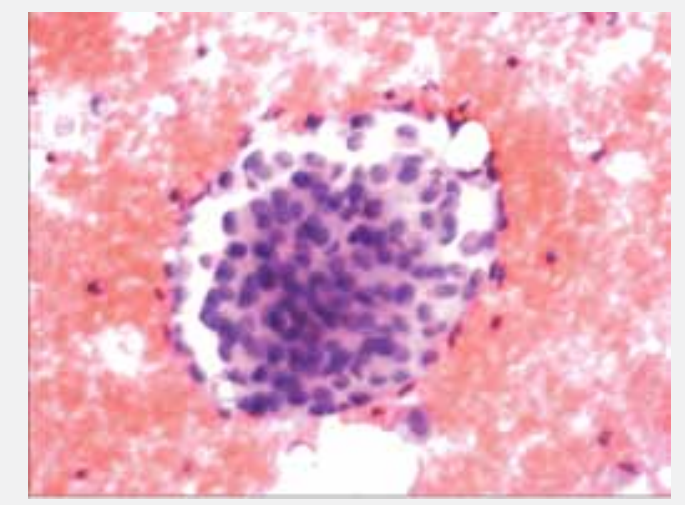

Figure 1 : Nipple discharge smear from Case 2 showing papillae in hemorrhagic background. X20, H\&E stain.

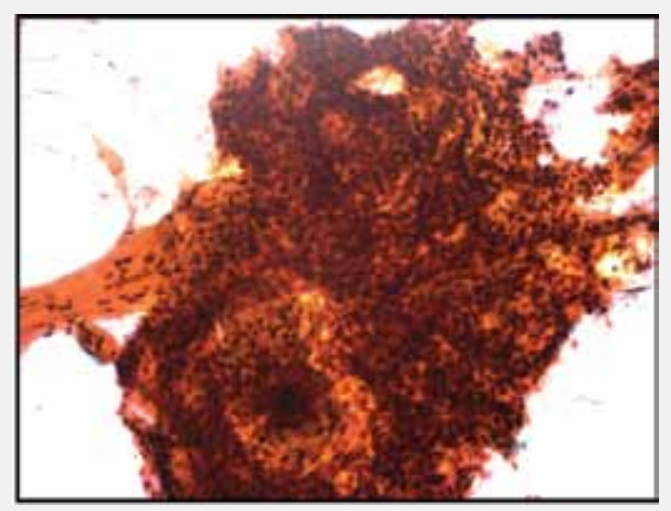

Figure 3: Smear from same case showing a three dimensional epithelial fragment with sclerotic fibrovascular core. X20, Papanicolau stain

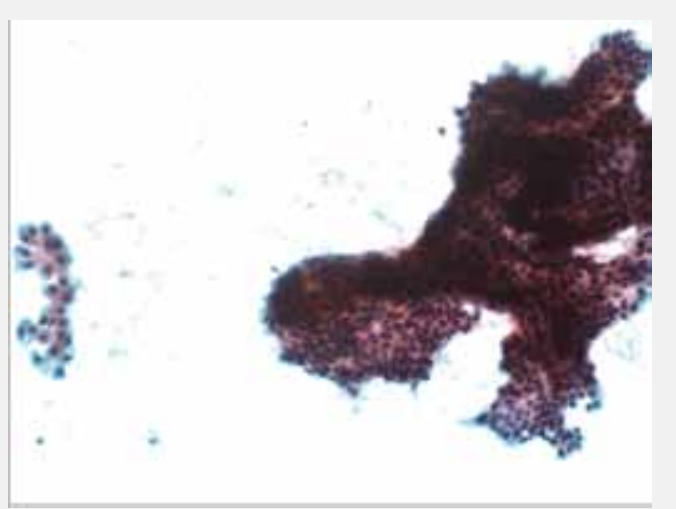

Figure 2 Cytology smear from Case 3 showing a complex branching epithelial fragment and a group of apocrine cells. X20, Papanicolau stain

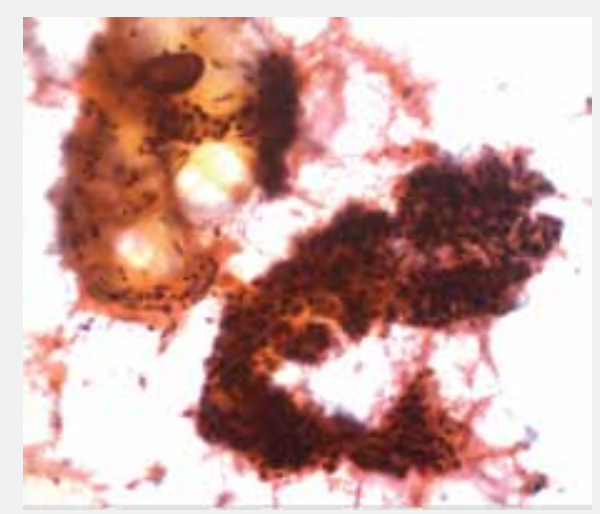

Figure 4: Smear from same case showing three dimensional complex epithelial fragment and microcalcification. X20, Papanicolau stain discharge cytology in 2 cases) showed discrepancy with histological diagnosis. The breakdown of these cases including cytologic and histological diagnosis and the most probable reason for pitfall is shown in tables 1-3. These included 22 females and one male with majority $(88 \%)$ in the age range of $25-50$ years. One patient was 17 years old and 2 were above 60 years.

There were 7 discrepant cases in the benign (C2) category (Table 1). Two cases of duct ectasia on nipple discharge without any palpable lump were diagnosed papillomatosis and ductal carcinoma in situ (DCIS) respectively after duct excision was performed due to a discrepant triple test. The case diagnosed as DCIS (Case 1) showed ductal cells of nuclear grade 1 but no microcalcification or comedonecrosis on histology. The patient had a greenish nipple discharge without any lump and review of the smears showed benign ductal cells in thick inspissated secretions in the background. The case of papillomatosis (Case 2) presented with a bloody nipple discharge and review of cytology showed isolated three dimensional papillary clusters and foamy macrophages without hemosiderin in a hemorrhagic background consistent with a papillary lesion (Figure 1).

Three cases reported as FCD (Cases 3-5) on FNA underwent lumpectomy due to clinicoradiological suspicion. Case 3 (Papillary carcinoma) showed nuclear grade 1 with predominantly intraductal component and microcalcifications on histology. This patient was 76 years old and had a small palpable lump $(0.8 \mathrm{~cm}$.). Cytology smears showed moderate cellularity, presence of benign ductal cells with no atypia, background apocrine cells, foam cells, and single bipolar nuclei suggesting a benign proliferative lesion possibly FCD (Figure 2). There were no columnar cells or siderophages. Review of the smears after review of literature on papillary lesions showed benign ductal cells in three dimensional fragments of variable sizes with and without fibrovascular core and microcalcification (Figure 3 and Figure 4). These features were overlooked in the initial diagnosis which should have alerted the pathologist. Case 4 (papillomatosis) 


\begin{tabular}{|l|l|l|l|l|}
\hline $\begin{array}{l}\text { Case } \\
\text { no. }\end{array}$ & $\begin{array}{l}\text { Cyto diagnosis } \\
\text { Initial }\end{array}$ & $\begin{array}{l}\text { Cyto diagnosis } \\
\text { Review by cytopathologist }\end{array}$ & Histo diagnosis & Reason for diagnostic pitfall /discrepancy \\
\hline 8. & $\begin{array}{l}\text { Benign inflammatory } \\
\text { lesion with atypia }\end{array}$ & Mastits & Mastits & $\begin{array}{l}\text { Interpretation error with the knowledge that benign } \\
\text { lesions can show atypia. Biopsy advised because of fear of } \\
\text { missing cancer. (False positive diagnosis on cytology). }\end{array}$ \\
\hline 9. & $\begin{array}{l}\text { Benign inflammatory } \\
\text { lesion with atypia }\end{array}$ & Mastits & Mastits & As above \\
\hline 10. & $\begin{array}{l}\text { Benign lesion with } \\
\text { atypia }\end{array}$ & Gynecomastia & Gynecomastia & As above \\
\hline 11. & $\begin{array}{l}\text { Benign lesion with } \\
\text { atypia }\end{array}$ & Benign lesion with atypia & fat necrosis & As above \\
\hline 12. & $\begin{array}{l}\text { Atypical ductal } \\
\text { hyperplasia }\end{array}$ & Atypical ductal hyperplasia & Fibroadenoma & Interpretation error due to the overlapping features. (False \\
\hline
\end{tabular}

Table 2: Cytohisto correlation and reasons of diagnostic pitfall in cytology (Category atypical C3, No.cases $=5$ )

\begin{tabular}{|l|l|l|l|l|}
\hline $\begin{array}{l}\text { Case } \\
\text { no }\end{array}$ & $\begin{array}{l}\text { Cyto diagnosis } \\
\text { Initial }\end{array}$ & $\begin{array}{l}\text { Cyto diagnosis } \\
\text { Review by cytopathologist }\end{array}$ & Histo diagnosis & Reason for diagnostic pitfall /discrepancy \\
\hline $\begin{array}{l}\text { 13. to } \\
20\end{array}$ & Atypical ductal cells & $\begin{array}{l}\text { unsatisfactory due to poor quality } \\
\text { smears (8) }\end{array}$ & $\begin{array}{l}\text { Fibrocystic disease (4), } \\
\text { Fibroadenoma (1), } \\
\text { Tubular adenoma (1), } \\
\text { Papillomatosis (2) }\end{array}$ & $\begin{array}{l}\text { Interpretation error due to atypia in poor quality smears } \\
\text { and biopsy advised because of fear of missing cancer. (False } \\
\text { positive diagnosis on cytology). }\end{array}$ \\
\hline 21. & Atypical ductal cells & Atypical ductal cells & Papillomatosis & Interpretation error due to overlapping features. (False \\
\hline
\end{tabular}

Table 3: Cytohisto correlation and reasons of diagnostic pitfall in cytology (Category suspicious C4, No. of cases = 9)

was suggestive of benign proliferative lesion on review cytology. Case 5 showing radial scar with atypical ductal hyperplasia $(\mathrm{ADH})$ on histology did not show any evidence of $\mathrm{ADH}$ on review of cytology smears.

Two cases (Case 6 and 7) of hamartoma and tubular adenoma respectively on histology were misclassified as FA on cytology (C2). Review of FNA smears of the hamartoma case showed moderate cellularity comprising intact lobules, adipose tissue, cohesive fragments of benign ductal cells, paucity of bipolar naked nuclei in the background, absence of staghorn epithelial fragments and stromal fragments.

C3 (atypical) category had 5 discrepant cases (Table 2). Four cases (Case 8-11) showed benign lesions on histology (gynecomastia, FA, severe mastitis and fat necrosis) and showed mild atypia on cytology. Case 12 was FA on histology but called ADH on cytology showed high cellularity, complex sheets showing cribriform pattern, focal nuclear atypia and mitosis.

Nine cases were reported as atypical cells suspicious for malignancy on cytology (C4) and a biopsy confirmation was advised (Table 3). These showed benign proliferative lesion on histology. Smears in 8 cases (Case 13-20) were received from our satellite centres and were of poor quality due to scant cellularity, clotted hemorrhagic material and air drying artifacts due to poor fixation leading to artifactual atypia. Clotting entrapped cellular material leading to loss of architecture and false impression of hyperchromasia. Excessive or vigorous smearing pressure caused disruption of cell aggregates and smudging of nuclear chromatin, which can mimic the loss of cohesion, nuclear enlargement and pleomorphism characteristic of malignant epithelial cells. Drying artifacts in alcohol-fixed Papanicolau stained smears led to nuclear enlargement and pale nuclei with smudged chromatin (Figure 5 and Figure 6).

One case of papillomatosis (Case 21) was misinterpreted as ADH on cytology. Two cases (Case 22 and 23) were positive for malignancy (C5) on cytology. Case 22 confirmed to be NHL by immunochemistry was mis- 


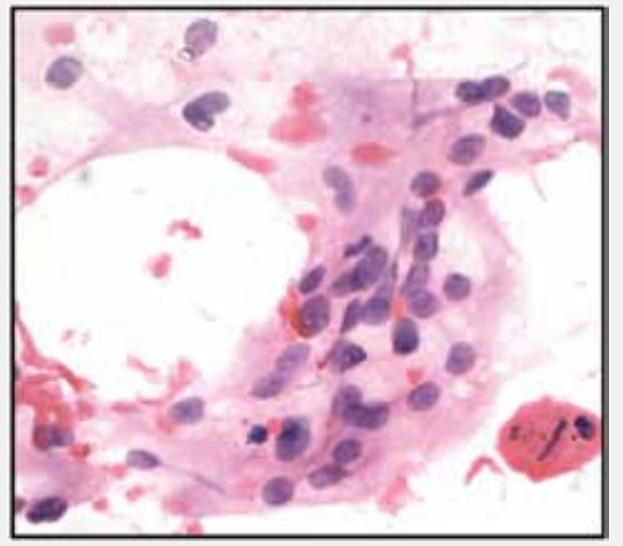

Figure 5: Poor quality smear showing air drying artifacts leading to false positive diagnosis. $X 40, H \& E$ stain

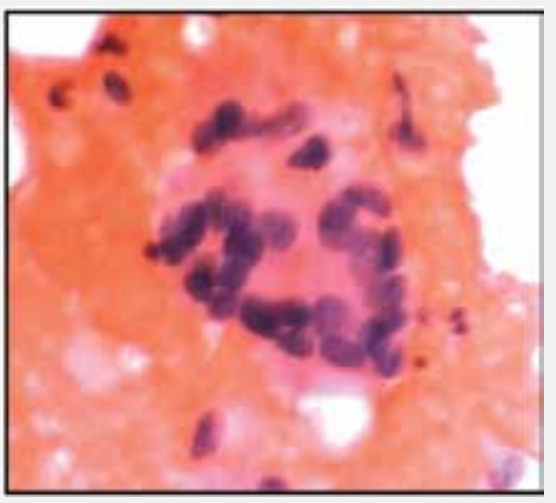

Figure 6: Poor quality smear showing clotted material in hemorrhagic background resulting in disruption of cell aggregate, smudging of nuclei, hyperchromasia, nuclear enlargement and pleomorphism. X40, $H \&$ stain classified as lobular carcinoma on cytology and showed monomorphic small cells, with scant cytoplasm, vesicular nuclei, and inconspicuous nucleoli in small aggregates and scattered singly. There were no intracytoplasmic lumens. Case 23 was mixed (lobular and ductal) carcinoma on histology. Review of the smears did not change initial diagnosis.

There was no major discrepancy between cytology and histology. Minor discrepancies resulted due to the interpretation errors in 16 cases, sampling errors in three cases and misclassification of subtypes within benign category and malignant category in 2 cases each. There was no false positive case in C5 category so the calculation of false positive rate was done for the 14 cases in atypical C3 and suspicious C4 category. Poor quality smears resulted in false positive interpretation error in 8 out of $14(57 \%)$ cases. There were 2 false negative cases in C2 category. Overall sensitivity was $91 \%$, specificity $79 \%$, positive predictive value (PPV) 59\% and negative predictive value (NPV) was $96 \%$. The number of cases in individual categories was too small to assess cytology performance in each category.

\section{Discussion}

An accurate and specific diagnosis on cytology is possible when FNA slides are adequate in terms of cellularity and technical preparation and adequate clinical data is available $(5,6)$.

Sampling errors result in a non representative sample in cytology which can occur due to inherent nature of the lesion such as ill defined lump (as in Cases 4), ex- tensive fibrosis in radial scar (in Case 5) and fibrosis in ILC (showed fibroadipose tissue on FNA in our series). Radial scar is known to yield poor cellularity on FNA due to extensive fibrosis (7). Among all breast cancers, ILC has the highest false negative or unsatisfactory rate. Due to a diffuse and discontinuous growth pattern with extensive fibrosis and involvement of the normal adipose tissue ILC often fail to form distinct mass and is difficult to palpate, aspirate or diagnose by mammography leading to the sampling error (8). Sampling error in nipple discharge cytology (Case 1) occurred due to low yield of diagnostic cells. It is well known that nipple discharge cytology in the absence of a lump has low sensitivity and specificity (9).

Interpretation errors resulted in false positive (atypical and suspicious) diagnosis in 14 cases. Reactive atypia can often be seen in mastitis, fat necrosis, gynecomastia, postoperative repair, and post radiation $(10,11)$. Correct clinical information is important. A history of previous tissue injury and the presence of acute inflammatory cells (not just lymphocytes) rarely seen in breast cancer call for caution and careful evaluation of the nuclear atypia. Overuse or casual application of the term atypia should be avoided. However fear of missing cancer led to the choice of $\mathrm{C} 3$ category in 5 cases in our series. Architectural complexity and cytological atypia including mitosis in FA are the most frequent causes of false positive diagnosis in breast FNA. The presence of myoepithelial cells (superimposed on the ductal cells and as bipolar naked nuclei) is a safeguard against an erroneous malignant diagnosis (10). 
Ideally all cases with poor quality of smears should be interpreted as unsatisfactory and repeat FNA should be advised. However it is not possible to repeat FNA in all the cases that have been aspirated outside the hospital as the patients have to travel long distances to come to our hospital for a repeat FNA. In Kenya where the incidence of breast cancer is high, there is fear of missing a cancer on cytology. The pathologists in our laboratory therefore prefer to advise biopsy so that any suspicion on cytology can be confirmed before the patient is lost to follow up. This is the most important cause of false alert in our series as by others $(6,7,10)$.

Interpretation error resulted in false negative diagnosis on cytology in two cases. Case 2 (papillomatosis on histology), was consistent with papillary lesion (C3) on review cytology. This was misinterpreted as duct ectasia (false negative) as the anatomic pathologist was not familiar with cytological diagnostic criteria. Bloody discharge always needs further exploration even if cytology is negative (12). Case 3 (papillary carcinoma on histology) had a small $(0.8 \mathrm{~cm})$ lesion. The presence of background apocrine cells, foam cells, and single bipolar nuclei suggested a benign lesion but in view of the age, and moderate cellularity there should have been a high index of suspicion on cytology. This case was reported under the pressure of a rapid diagnosis for the One Stop Breast Clinic. A false negative diagnosis is possible, particularly if a papillary architecture is not identified as in our case due to non familiarity with this morphology. Cytologic criteria for the accurate diagnosis of papillary lesions are not yet well established. Some criteria are emerging and require experience (13-15). However, they are not distinctive enough and rapid diagnosis under pressure can aggravate such interpretation errors (16).

Lipoma is an example of common misinterpretation in breast FNA. It is not possible to differentiate normal adipose tissue of breast from lipoma. Mammography and ultrasound are also less sensitive in detecting a breast lipoma. If FNA repeatedly yields fibroadipose tissue in a clinically benign lesion the possibility of a lipoma should be entertained provided that the aspirator is sure about having been in the target and sampled the lesion adequately (17).

Error in subtyping of a benign or malignant lesion can occur due to overlapping features. Cytological features of TA (Case 6) and hamartoma (Case 7) can overlap with FA and are not always distinguishable (18-19). Pri- mary breast lymphoma (Case 22) can be misdiagnosed as carcinoma on cytology. Immunohistochemistry and/ or flow cytometry is helpful in differentiating it from carcinoma (20). Low grade ductal carcinoma and lobular carcinoma (Case 23) have overlapping cytologic features (10). This error diminishes with increasing experience in breast cytology and adherence to strict diagnostic criteria.

The sensitivity, specificity and PPV of FNA at any centre depends upon who performs the procedure, level of experience of the pathologist or cytopathologist and whether interpretation is done by a cytopathologist or histopathologist, one or many persons, the type of reporting system followed and availability of follow up histology $(5,6)$. In breast a sensitivity of $72-99 \%$ and specificity of $98-100 \%$ has been reported in the literature $(10,21,22)$. Our sensitivity of $91 \%$ is well within the range, however our specificity of $79 \%$ is slightly lower. This reflects our low false negative rate but high false positive rate. This false positive rate in our series was restricted to the atypical (C3) and suspicious (C4) category which is not false positive in the true sense as compared to C5 category which is considered true false positive in other series because it can seriously affect management. A conservative approach was applied for cases in $\mathrm{C} 3$ and $\mathrm{C} 4$ categories using the triple test which resulted in core biopsy or lumpectomy and never a mastectomy. This approach is justified by low PPV (59\%) of $\mathrm{C} 3$ and C4 categories in our series. Any inappropriate clinical decision can therefore be avoided. There is negligible risk of overtreatment. Our high negative predictive value of $96 \%$ gives confidence to our surgeons in reassuring these patients and allaying anxiety.

All types of errors discussed above call for the corrective measures on the part of both pathologist and sample provider. The expertise of a full time cytopathologist (NK) is now available in our laboratory who provides the confidence to report the samples that cannot be evaluated due to the technical factors such as sparse cellularity, obscuring blood, air-drying artifacts as unsatisfactory and not as "atypical" or "suspicious". FNA procedure is performed by the cytopathologist or by a resident under supervision. Use of a 23 gauge needle with suction technique, making adequate number (3-4) of passes, naked eye examination of unstained slides for adequacy, rapid staining to evaluate adequacy in selected cases and repeating FNA in the same sitting if inadequate are other 


\title{
Addressing the challenges of practicing breast cytology in a tertiary teaching hospital in Kenya
}

\author{
Kumar N, Sayed S Moloo Z, Chauhan R, Wasike R
}

helpful measures that are implemented.

To improve the quality of smears received through our satellite centres and clinics, an FNA clinic is run once a week by the cytopathologist and residents in our outreach laboratories. To address the suboptimal technique, training in FNA procedure is being organized by our cytopatholgist free of cost for the sample providers to help them develop skills in both aspiration and smear preparation. They also come to our department or our satellite centre during FNA clinic to learn the technique on individual basis.

To summarize, there was no major discrepancy to adversely influence the management or prognosis significantly in our series due to use of triple test approach. Minor discrepancies resulted due to sampling and interpretation errors. Poor quality smear received from outside our institution emerged as a major cause of interpretation errors.

We recommend that to make the best use of this cost effective technique, training in FNA procedure and smear preparation for medical personnel is necessary. Cytology is a specialized discipline of pathology. All anatomic pathologists and residents must be tutored in cytology interpretation with the help of local cytopathologists and other opportunities available at the national and international level. For example cytology tutorials are held in developing countries by the international faculty with support from Papanicolaou Society of Cytopathology and local professional bodies (23).

\section{References}

1. Mutuma G .Z and Rugutt-Korir A. Cancer incidence report (2000 - 2002). Nairobi Cancer Registry, Kenya Medical Research Institute, Publisher Roche Products, Nairobi, Kenya, 2006

2. Kocjan G. Needle aspiration cytology of the breast: current perspective on the role in diagnosis and management. Acta Med Croatica 2008; 62(4):391-401.

3. Kumar N, Sayed S, Moloo Z et al. Global perspectives: the quest for Knowledge in Cytopathology Laboratory. " Cytopathology Laboratory at the Aga Khan University Hospital in Nairobi, Kenya". The Bulletin, American Society of Cytopathology, September 2010, Vol. XLVII (5): 132-135

4. National Cancer Institute. Uniform approach to breast fineneedle aspiration biopsy. Diagn Cytopathol 1997;16:295311

5. Dray M, Mayall F, Darlington A. Improved fine needle aspi- ration (FNA) cytology results with a near-patient diagnosis service for breast lesions. Cytopathol 2000;11:32-7.

6. Lee KR, et al. Fine Needle Aspiration of the breast: The importance of the aspirator. Acta Cytol 1987;31:281-284

7. Kline TS, Joshi LP, Neal HS: Fine needle aspiration of the breast. Diagnosis and pitfalls: A review of 3545 cases. Cancer 1979; 44: 1458-1464.

8. Arpino G, Bardou VJ, Clark GM et al. Infiltrating lobular carcinoma of the breast: tumor characteristics and clinical outcome. Breast Cancer Res 2004, 6:R149-R156

9. Takeda T, Matsui A, Sato Y, et al. Nipple discharge cytology in mass screening for breast cancer. Acta Cytol 1990, 34:161- 4.

10. Orell SR, Miliauskas J. Fine needle biopsy cytology of breast lesions: A Review of Interpretative Difficulties. Adv in Anat Pathol 2005,12;5: 233-245

11. Amrikachi M, Green LK, Rone R, et al. Gynecomastia: cytologic features and diagnostic pitfalls in fine needle aspirates. Acta Cytol 2001;45(6):948-52.

12. Singh M, Kumar N, Jain S. Exfoliative cytology of abnormal nipple discharge. Journal of Cytology, 1999;16: 21-26

13. Field A, Mak, A. A Prospective study of the diagnostic accuracy of cytological criteria in the FNAB diagnosis of breast papillomas. Diagn Cytopathol 2007;35:465-475

14. Michael CW, Buschmann B. Can true papillary neoplasms of breast and their mimickers be accurately classified by cytology? Cancer Cytopathol 2002;96:92-100.

15. Gomez-Aracil V, Mayayo E, Azua J et al. Papillary neoplasms of the breast: clues in fine needle aspiration cytology. Cytopathology 2002; 13, 22-30

16. Zuk JA, Maudsley G, Zakhour HD. Rapid reporting on fine needle aspiration of breast lumps in outpatients. J Clin Pathol 1989;42: 906-11.

17. Lanng C, Eriksen BO, Hoffmann J, et al. Lipoma of the breast: a diagnostic dilemma. Breast 2004;13(5):408-11.

18. Kumar N, Kapila K, Verma K. Characterization of tubular adenoma of breast-diagnostic problem in fine needle aspirates. Cytopathology 1998;9:301-307

19. Herbert M, Schvimer M, Zehavi S, et al. Breast hamartoma: fine-needle aspiration cytologic finding. Cancer 2003,25;99(4):255-8

20. Duncan VE, Reddy VB, Jhala NC, et al. Non-Hodgkin's lymphoma of the breast: a review of 18 primary and secondary cases. Ann of diag pathol 2006,10: 144-148

21. Giard RW, Hermans J. The value of aspiration cytology examination of the breast. A statistical review of the medical literature. Cancer 1992; 69:2104-7

22. Ciatto $S$, Bonardi R, Cariaggi MP. Performance of fine-needle 
aspiration cytology of the breast-multicenter study of 23,063 aspirates in ten Italian laboratories. Tumori. 1995; 81(1):137

23. Field A, Jarka M, Geddie W, et al. Assisting cytopathology training in medically under resourced countries- defining the problem and establishing solutions. Diag Cytopathol, 2010 (in Press) 